Research Article

\title{
Microstructural and Optical Characterization of Heterostructures of ZnS/CdS and CdS/ZnS Synthesized by Chemical Bath Deposition Method
}

\author{
Temesgen Geremew ${ }^{1}$ and Tizazu Abza $\mathbb{D}^{2}$ \\ ${ }^{1}$ Bule Hora University, Physics Department, Bule Hora, Ethiopia \\ ${ }^{2}$ Hawassa University, Physics Department, Hawassa, Ethiopia \\ Correspondence should be addressed to Tizazu Abza; zabishwork2@gmail.com
}

Received 8 August 2020; Revised 4 November 2020; Accepted 16 November 2020; Published 21 November 2020

Academic Editor: Miguel Navarro-Cia

Copyright (c) 2020 Temesgen Geremew and Tizazu Abza. This is an open access article distributed under the Creative Commons Attribution License, which permits unrestricted use, distribution, and reproduction in any medium, provided the original work is properly cited.

$\mathrm{ZnS} /$ glass and $\mathrm{CdS} /$ glass single layers and $\mathrm{ZnS} / \mathrm{CdS}$ and $\mathrm{CdS} / \mathrm{ZnS}$ heterojunction thin films were deposited by the chemical bath deposition method using zinc acetate and cadmium acetate as the metal ion sources and thioacetamide as a nonmetallic ion source in acidic medium. $\mathrm{Na}_{2}$ EDTA was used as a complexing agent to control the free cation concentration. The single layer and heterojunction thin films were characterized with X-ray diffraction (XRD), a scanning electron microscope (SEM), energy dispersive X-ray (EDX), and a UV-VIS spectrometer. The XRD patterns of the CdS/glass thin film deposited on the soda lime glass substrate crystalized in the cubic structure with a single peak along the (111) plane. The $\mathrm{ZnS} / \mathrm{CdS}$ heterojunction and $\mathrm{ZnS} / \mathrm{glass}$ single layer thin films were crystalized in the hexagonal $\mathrm{ZnS}$ structure. The CdS/ZnS heterojunction thin film is nearly amorphous. The optical analysis results confirmed single band gap values of $2.75 \mathrm{eV}$ and $2.5 \mathrm{eV}$ for $\mathrm{ZnS} / \mathrm{CdS}$ and CdS/ZnS heterojunction thin films, respectively. The CdS/glass and CdS/ZnS thin films have more imaginary dielectric components than the real part. The optical conductivity of the single layer and heterojunction films is in the order of $10^{15} \mathrm{1} / \mathrm{s}$. The optical study also confirmed refractive index values between 2 and 2.7 for $\mathrm{ZnS} /$ glass, $\mathrm{ZnS} / \mathrm{CdS}$, and $\mathrm{CdS} / \mathrm{ZnS}$ thin films for incident photon energies between $1.2 \mathrm{eV}$ and $3.8 \mathrm{eV}$. The surface morphology studies revealed compacted spherical grains covering the substrate surfaces with few cracks on ZnS/glass, ZnS/CdS, and CdS/glass and voids on CdS/ZnS thin films. The EDX result confirmed nearly $1: 1$ metallic to nonmetallic ion ratio in the single-layered thin films and the dominance of $\mathrm{Zn}$ ion over $\mathrm{Cd}$ ion in both $\mathrm{ZnS} / \mathrm{CdS}$ and $\mathrm{CdS} / \mathrm{ZnS}$ heterojunction thin films.

\section{Introduction}

Wide band gap II-VI compounds have received a lot of attention as optoelectronic materials. Cadmium sulfide (CdS) and zinc sulfide (ZnS) are II-VI compound semiconductors with wide direct bandgaps of $2.42 \mathrm{eV}$ and $3.54 \mathrm{eV}$, respectively $[1,2]$. CdS and ZnS can crystalize in both cubic and hexagonal structures depending on the synthesis procedures and the thermal and chemical treatments [3,4]. CdS is an $n$-type semiconductor used in a variety of applications, such as the window layer in highefficiency solar cells' heterostructures, in optical detectors, optoelectronic devices, light-emitting diodes, photonic devices, photoconductive sensors, and environmental control [5-7]. ZnS is also an $n$-type semiconductor [8] with promising applications in solar control coating, optical and chemical sensors, and optoelectronic devices, such as electroluminescent devices, light-emitting diodes, lasers, and photovoltaic cells $[9,10]$. Most single layer photocatalytic and optoelectronic devices suffer exploitation of limited range of solar spectrum and high recombination rate of photo-generated charge carriers leading to a limited efficiency of the devices [11]. A heterojunction is a contact interface formed as a result of hybridization between two semiconductors with dissimilar band and electronic structures in a way that results in band alignment [12]. 
Semiconductor heterojunction has opened up new horizons in materials science and led to exciting new developments in many scientific areas $[13,14]$. It offers extra degrees of freedom in the design of semiconductor junction devices due to the controlled impurity doping and the conduction and valence band offsets at the junction $[11,15]$. The heterojunctions are the fundamental platform for the outstanding performance of many important optoelectronic and photocatalytic device applications such as lasers, lightemitting diodes, solar cells, and high electron mobility transistors [16]. The $\mathrm{ZnS} / \mathrm{CdS}$ and $\mathrm{CdS} / \mathrm{ZnS}$ heterojunctions are potential materials for efficient optoelectronic and photocatalytic applications in the blue or ultraviolet region [17]. They can be used as an $n$-type buffer layer to form thin film heterojunction solar cells $[18,19]$, quantum wells [20], and light-emitting devices [21] with a better performance than CdS and ZnS single layers. Therefore, the study of these heterojunctions is of great significance for the development of such device applications. Different methods have been used to fabricate $\mathrm{ZnS} / \mathrm{CdS}$ and $\mathrm{CdS} / \mathrm{ZnS}$ heterojunction thin films, e.g., CBD $[22,23]$, the vacuum deposition method [24, 25], electrodeposition [19, 26], screen printing [27], nonreactive RF magnetron sputtering [28], pulsed laser deposition [29], and others. The CBD has many benefits such as low cost for equipment and operation, simplicity in operation, low deposition temperature, low energy consumption, and large area deposition in a single procedure $[22,30]$.

There are very few reports on chemical bath-deposited $\mathrm{CdS} / \mathrm{ZnS}$ and $\mathrm{ZnS} / \mathrm{CdS}$ heterojunction thin films [18, 22, 23] in the alkaline condition. Deposition conditions, such as the bath $\mathrm{pH}$, have a significant influence on the deposition mechanism and hence the nature of the final product. As far as the authors are aware, there is no report on the acidic bath-deposited $\mathrm{ZnS} / \mathrm{CdS}$ or $\mathrm{CdS} / \mathrm{ZnS}$ heterojunction thin films. In this work, we report the study of structural, morphological, compositional, and optical properties of chemical bath-deposited $\mathrm{ZnS} / \mathrm{CdS}$ and $\mathrm{CdS} / \mathrm{ZnS}$ heterojunction thin films in acidic chemical baths.

\section{Experimental Techniques}

$\mathrm{ZnS}$ and $\mathrm{CdS}$ single layers thin films were deposited on soda lime glass slide substrates. Before the deposition, the slides were cleaned in the following subsequent procedures: immersed in nitric acid for $12 \mathrm{~h}$, washed with distilled water, immersed in ethanol for $30 \mathrm{~min}$, washed with distilled water, and dried in ambient conditions. The $\mathrm{ZnS}$ single layer thin film was synthesized from a solution containing aqueous solutions of $6 \mathrm{ml}(0.5 \mathrm{M})$ zinc acetate, $3 \mathrm{ml}(0.2 \mathrm{M})$ $\mathrm{Na}_{2}$ EDTA, $10 \mathrm{ml}(1 \mathrm{M})$ thioacetamide, and $46 \mathrm{ml}$ of distilled water in a $100 \mathrm{ml}$ vessel. The $\mathrm{pH}$ of the solution was adjusted to 2.5 by adding sufficient amount of $\mathrm{HCl}$ into this solution. The deposition solution was prepared under continuous magnetic stirring at room temperature. The bath temperature was adjusted to $80^{\circ} \mathrm{C}$, and the cleaned glass substrates were suspended vertically by the cover of the vessel. After $30 \mathrm{~min}$, the colorless solution changed to milky indicating formation of the $\mathrm{ZnS}$. The thin films were removed from the bath after 60 min deposition, washed thoroughly with distilled water, and dried in ambient condition. Similarly, the $\mathrm{CdS}$ single layer thin film was prepared from aqueous solution of $22.5 \mathrm{ml}(0.2 \mathrm{M})$ cadmium acetate, $3 \mathrm{ml}(0.2 \mathrm{M})$ $\mathrm{Na}_{2}$ EDTA, $10 \mathrm{ml}(1 \mathrm{M})$ of thioacetamide, and $54.5 \mathrm{ml}$ distilled water in $100 \mathrm{ml}$ vessel for a period of $90 \mathrm{~min}$ at a $\mathrm{pH}$ of 2.5 and bath temperature of $80^{\circ} \mathrm{C}$. The synthesized $\mathrm{ZnS}$ and $\mathrm{CdS}$ single layer thin films were used as a substrate for the preparation of $\mathrm{CdS} / \mathrm{ZnS}$ and $\mathrm{ZnS} / \mathrm{CdS}$ heterojunction thin films, respectively, at the same conditions to that of the corresponding single layer thin films on soda lime glass substrates.

The deposition process is based on the slow release of $\mathrm{Zn}^{2+}, \mathrm{Cd}^{2+}$, and $\mathrm{S}^{2-}$ ions in a solution which then condense on the substrate. The deposition of $\mathrm{ZnS}$ occurs when the ionic product of $\mathrm{Zn}^{2+}$ and $\mathrm{S}^{2-}$ exceeds the solubility product of $\mathrm{ZnS}$. Zinc acetate $\left(\mathrm{Zn}\left(\mathrm{CH}_{3} \mathrm{COO}\right)_{2}\right)$ was used as the $\mathrm{Zn}^{2+}$ ion source, and thioacetamide $\left(\mathrm{C}_{2} \mathrm{H}_{5} \mathrm{NS}\right)$ provided $\mathrm{S}^{2-}$ ions. The generation of these ions and the deposition of the films are explained. The expected chemical equation of the reaction for the deposition of $\mathrm{ZnS}$ is as follows:

$$
\mathrm{H}_{3} \mathrm{C}: \mathrm{C}(\mathrm{S}) \mathrm{NH}_{2}+2 \mathrm{H}_{2} \mathrm{O} \longrightarrow \mathrm{CH}_{3} \mathrm{COOH}+\mathrm{H}_{2} \mathrm{~S}+\mathrm{NH}_{3} \text {. }
$$

This reaction can proceed by two pathways, one in which the carbon-sulfur bond is broken first [31]:

$$
\mathrm{H}_{3} \mathrm{C}: \mathrm{C}(\mathrm{S}) \mathrm{NH}_{2}+2 \mathrm{H}_{2} \mathrm{O} \longrightarrow \mathrm{CH}_{3} \mathrm{C}: \mathrm{C}(\mathrm{O}) \mathrm{NH}_{2}+\mathrm{H}_{2} \mathrm{~S} \text {, }
$$

forming acetamide as an intermediate or a pathway in which the carbon-nitrogen bond is first broken to give thioacetic acid:

$$
\mathrm{H}_{3} \mathrm{C}: \mathrm{C}(\mathrm{S}) \mathrm{NH}_{2}+\mathrm{H}_{2} \mathrm{O} \longrightarrow \mathrm{CH}_{3} \mathrm{C}: \mathrm{C}(\mathrm{S}) \mathrm{OH}+\mathrm{NH}_{3},
$$

which then is hydrolyzed to $\mathrm{H}_{2} \mathrm{~S}$ and acetic acid. The $\mathrm{H}_{2} \mathrm{~S}$ dissolves in water as hydrosulphide ion:

$$
\mathrm{H}_{2} \mathrm{~S}+\mathrm{H}_{2} \mathrm{O} \rightleftarrows \mathrm{HS}^{-}+\mathrm{H}_{3} \mathrm{O}^{+} \text {. }
$$

The hydrosulphide ion again dissolves to sulfur ion:

$$
\mathrm{HS}^{-}+\mathrm{H}_{2} \mathrm{O} \rightleftarrows \mathrm{H}_{3} \mathrm{O}^{+}+\mathrm{S}^{2-} \text {. }
$$

The zinc ion $\mathrm{Zn}^{2+}$ is released from zinc acetate:

$$
\left(\mathrm{Zn}\left(\mathrm{CH}_{3} \mathrm{COO}\right)_{2}\right) \leftrightarrow \mathrm{Zn}^{2+}+2 \mathrm{CH}_{3} \mathrm{COO}^{-} \text {. }
$$

Therefore, the overall reaction becomes

$$
\mathrm{Zn}^{2+}+\mathrm{S}^{2-} \longrightarrow \mathrm{ZnS} \text {. }
$$

Using similar procedure, cadmium acetate $\left(\mathrm{Cd}\left(\mathrm{CH}_{3} \mathrm{COO}\right)_{2}\right)$ was used as the $\mathrm{Cd}^{2+}$ ion source, and thioacetamide $\left(\mathrm{C}_{2} \mathrm{H}_{5} \mathrm{NS}\right)$ provided $\mathrm{S}^{2-}$ ions through hydrolysis in an acidic medium. So that, the overall reaction becomes

$$
\mathrm{Cd}^{2+}+\mathrm{S}^{2-} \longrightarrow \mathrm{CdS}
$$


The thickness of the ZnS/glass, ZnS/CdS, CdS/glass, and $\mathrm{CdS} / \mathrm{ZnS}$ thin films were measured by the gravimetric method. For the $\mathrm{ZnS} / \mathrm{CdS}$ and $\mathrm{CdS} / \mathrm{ZnS}$ heterojunctions, the weight difference was measured after the deposition of each layer. Using the bulk density of $\mathrm{ZnS}$ and $\mathrm{CdS}$, the thicknesses of the $\mathrm{ZnS} /$ glass, $\mathrm{ZnS} / \mathrm{CdS}$, CdS/glass, and $\mathrm{CdS} / \mathrm{ZnS}$ thin films were calculated to be $0.31,0.48,0.20$, and $0.37 \mu \mathrm{m}$, respectively. The optical and solid state properties of the heterostructures of $\mathrm{ZnS}$ and $\mathrm{CdS}$ thin films were determined from the absorption spectrum using the Shimadzu UV-3600 plus UV-Vis spectrophotometer within the wavelength range of $300 \mathrm{~nm}-1000 \mathrm{~nm}$. Structural characterization of the films was carried out by the Bruker D8 X-ray diffractometer (XRD) with $\mathrm{CuK} \alpha(\lambda=1.54060 \mathrm{~A})$ radiation working at $40 \mathrm{~mA}$ and $40 \mathrm{kV}$ at a scan rate of $0.03^{\circ} / \mathrm{s}$. The XRD patterns were analyzed by matching the observed peaks with the standard JCPDS files. The surface morphology and composition of the as deposited thin films were assessed by the ZEISS sigma field effect scanning electron microscopy (FE-SEM) integrated with ZEISS analysis station energy dispersive X-ray (EDX) device.

\section{Results and Discussion}

3.1. Structural Studies. Figure 1 shows the XRD patterns of $\mathrm{CdS}, \mathrm{ZnS}, \mathrm{ZnS} / \mathrm{CdS}$, and $\mathrm{CdS} / \mathrm{ZnS}$ single layers and heterojunction thin films. The CdS/glass single layer thin film shows well-defined single peak at $2 \theta=26.7^{\circ}$ corresponding to the (111) plane of the cubic CdS structure (JCPDS \#00010-0454). The presence of intense single peak in the XRD pattern of the CdS/glass single layer thin film indicates high crystallinity with highly restricted growth orientation of crystallites along the (111) plane. Similar results were reported by many authors $[32,33]$. On the other hand, the XRD pattern of the $\mathrm{ZnS}$ single-layered thin film shows four faint peaks along the (0024), (014), (0028), and (117) planes of the hexagonal structure (JCPDS \# 01-089-2174). These broad and faint peaks confirm the nanocrystallinity of the films as shown quantitatively in Table 1.

The XRD pattern of the $\mathrm{ZnS} / \mathrm{CdS}$ heterojunction thin film is nearly similar to that of the $\mathrm{ZnS} /$ glass single layer thin film; however, the intensity of the peaks improved. The improvement in the crystallinity of the $\mathrm{ZnS} / \mathrm{CdS}$ heterojunction signifies that $\mathrm{CdS}$ substrates promote the growth of hexagonal ZnS than the soda lime glass substrate. In contrast, the CdS/ZnS heterojunction thin film has two very weak XRD peaks along (0028) and (117) planes of the hexagonal ZnS structure. The absence of reflection from the $\mathrm{CdS}$ structure reveals the unsuitability of the $\mathrm{ZnS}$ substrate for the growth of the sufficient layer of CdS to diffract the $\mathrm{X}$-ray. The broad hump in the $2 \theta$ range of $20^{\circ}$ to $35^{\circ}$ observed on the XRD patterns of all the samples is due to the glass substrate [34].

The interplanar spacing $d_{h k l}$ between the different lattice planes was calculated from the Bragg diffraction law given as

$$
n \lambda=2 d_{h k l} \sin \theta_{h k l},
$$

where $n$ is the reflection order normally equal to unity, $\theta$ is the Bragg angle corresponding to $(h k l)$ planes, and

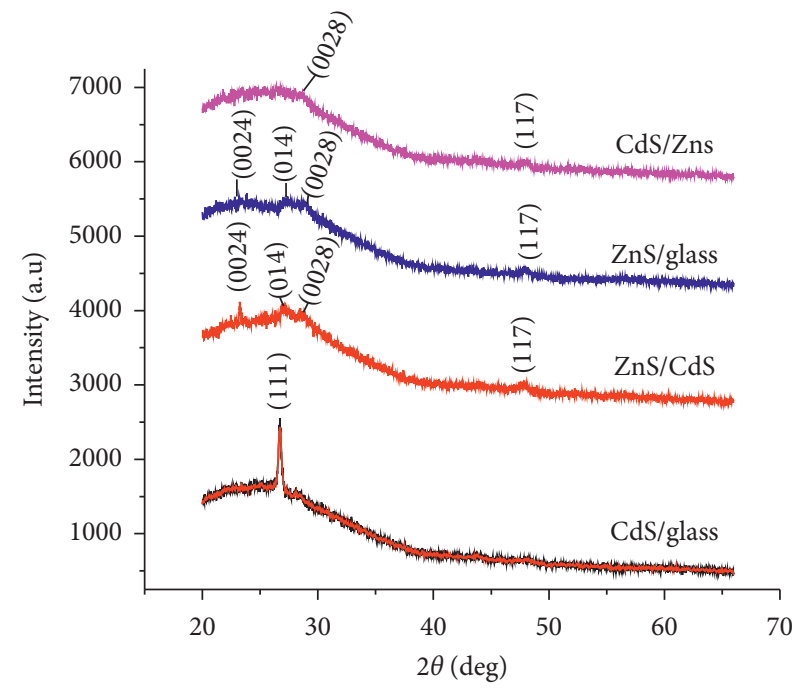

Figure 1: XRD patterns of CdS, ZnS, CdS/ZnS, and ZnS/CdS thin films.

$\lambda=0.15406 \mathrm{~nm}$ is the wavelength of the X-ray. The crystallite size, $D$, of the heterojunction and single-layered thin films was calculated by the Scherrer formula:

$$
D=\frac{k \lambda}{\beta \cos \theta},
$$

where $\beta$ is the full width at half maximum measured in radians, and $k$ is the constant known as the shape factor, taken as 0.9 for spherical-shaped crystallizes [35]. The lattice parameters, $a$ and $c$, of the hexagonal single and heterojunction thin films were evaluated by the following relation [36]:

$$
\frac{1}{d^{2} h k l}=\frac{4}{3} \frac{h^{2}+h k+k^{2}}{a^{2}}+\frac{l^{2}}{c^{2}}
$$

The lattice parameter, $a$, for the cubic structure was obtained by the following relation:

$$
a=d_{h k l} \sqrt{h^{2}+k^{2}+l^{2}}
$$

The calculated lattice constants are listed in Table 2. The crystallite size along the various planes of the $\mathrm{ZnS} / \mathrm{CdS}$ heterojunction thin film improved compared to the $\mathrm{ZnS} /$ glass single layer except along the (117) plane (Table 1). All the calculated $d$-spacing results agree well with the standard value with percentage difference less than $1 \%$ with exception along the (0024) plane which is about $4.75 \%$ for the $\mathrm{ZnS} / \mathrm{CdS}$ heterojunction film and $3.4 \%$ for the $\mathrm{ZnS} /$ glass single layer film. The maximum percentage variation between the calculated and standard lattice constants is less than $0.7 \%$. The present structural results show the influence of the substrate on the crystal structural parameters.

\subsection{Optical Analysis}

3.2.1. Optical Absorption and Band Gap. The absorption spectra of CdS/glass and $\mathrm{ZnS} /$ glass single layers and heterojunction thin films are shown in Figure 2(a). The ZnS/ 
TABLE 1: Some standard, observed, and calculated structural parameters of CdS/glass, CdS/ZnS, ZnS/glass, and ZnS/CdS thin films (JCPDS \# used 00-010-0454 for cubic CdS and 01-089-2174 for hexagonal ZnS).

\begin{tabular}{|c|c|c|c|c|c|c|c|c|}
\hline Sample & $2 \theta(\mathrm{deg})$ & Phase & Index & FWHM (deg) & $\mathrm{D}(\mathrm{nm})$ & $\varepsilon(\mathrm{x} 10-3)$ & Standard $d$-spacing $(\AA)$ & Observed $d$-spacing $(\AA)$ \\
\hline \multirow[t]{2}{*}{ CdS/glass } & 26.71 & $\mathrm{CdS}(\mathrm{C})$ & (111) & 0.35716 & 22.86 & 1.5158 & 3.3600 & 3.3351 \\
\hline & 23.23 & $\mathrm{ZnS}(\mathrm{H})$ & $(0024)$ & 0.4705 & 17.24 & 2.0107 & 3.6447 & 3.8179 \\
\hline \multirow{3}{*}{$\mathrm{ZnS} / \mathrm{CdS}$} & 27.18 & $\mathrm{ZnS}(\mathrm{H})$ & $(014)$ & 0.7829 & 10.44 & 3.3203 & 3.2735 & 3.2788 \\
\hline & 28.57 & $\mathrm{ZnS}(\mathrm{H})$ & $(0028)$ & 0.5956 & 13.76 & 2.5185 & 3.1240 & 3.1217 \\
\hline & 47.80 & $\mathrm{ZnS}(\mathrm{H})$ & $(117)$ & 1.1077 & 7.85 & 4.4186 & 1.8900 & 1.9011 \\
\hline \multirow{4}{*}{ ZnS/glass } & 23.59 & $\mathrm{ZnS}(\mathrm{H})$ & $(0024)$ & 1.9336 & 4.19 & 8.2586 & 3.6447 & 3.7684 \\
\hline & 27.32 & $\mathrm{ZnS}(\mathrm{H})$ & $(014)$ & 0.7851 & 10.41 & 3.3288 & 3.2735 & 3.2673 \\
\hline & 28.52 & $\mathrm{ZnS}(\mathrm{H})$ & $(0028)$ & 0.9209 & 8.90 & 3.8945 & 3.1240 & 3.1274 \\
\hline & 47.98 & $\mathrm{ZnS}(\mathrm{H})$ & $(117)$ & 0.8278 & 10.50 & 3.3001 & 1.8900 & 1.8947 \\
\hline \multirow{2}{*}{$\mathrm{CdS} / \mathrm{ZnS}$} & 28.53 & $\mathrm{ZnS}(\mathrm{H})$ & (0028) & 1.1022 & 7.43 & 4.6608 & 3.1240 & 3.1263 \\
\hline & 47.99 & $\mathrm{ZnS}(\mathrm{H})$ & $(117)$ & 0.9790 & 8.88 & 3.9023 & 1.8900 & 1.8942 \\
\hline
\end{tabular}

The letters " $\mathrm{C}$ " and " $\mathrm{H}$ " refer the cubic and hexagonal structures, respectively.

TABLE 2: The standard and calculated lattice parameters of CdS/glass, CdS/ZnS, ZnS/glass, and ZnS/CdS thin films (JCPDS \# used 00-0100454 for cubic CdS and 01-089-2174 for hexagonal ZnS).

\begin{tabular}{lcccc}
\hline Sample & Standard $a(\AA)$ & Observed $a(\AA)$ & Standard $c(\AA)$ & Observed $c(\AA)$ \\
\hline CdS/glass & 5.811 & 5.7765 & 6.716 & 6.6701 \\
ZnS/CdS & 3.823 & 3.8294 & 87.472 & 87.4079 \\
ZnS/glass & 3.823 & 3.8095 & 87.472 & 87.5684 \\
CdS/ZnS & 3.823 & 3.8326 & 87.432 & 87.5353 \\
\hline
\end{tabular}

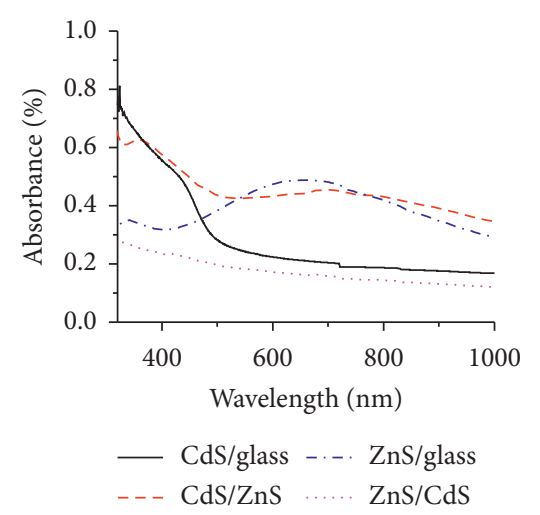

(a)

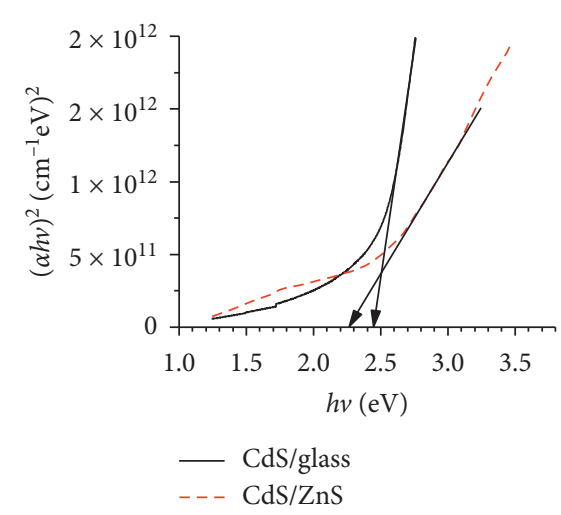

(b)

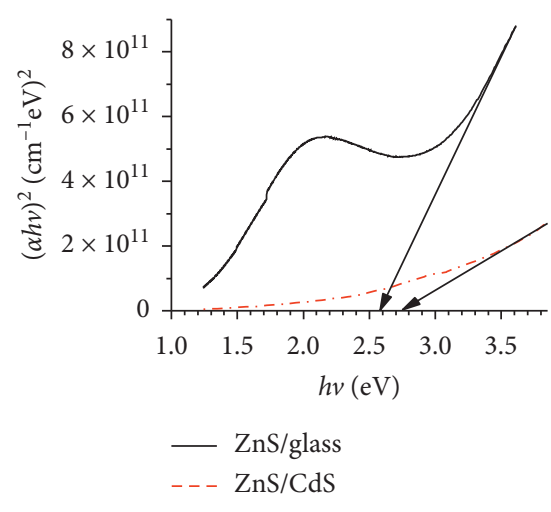

(c)

Figure 2: Optical absorbance and optical bandgaps of CdS/glass, CdS/ZnS, ZnS/glass, and ZnS/CdS thin films.

glass and $\mathrm{CdS} / \mathrm{ZnS}$ thin films have higher absorbance than that of $\mathrm{CdS} /$ glass and $\mathrm{ZnS} / \mathrm{CdS}$ thin films in the visible and infrared regions, which could be resulted from the existence of some defect states in the $\mathrm{ZnS}$ layer than that of the CdS [37]. The absorption edge for the $\mathrm{ZnS} /$ glass thin film, immediately before the onset of fundamental absorption (Figure 2), is expected due to the excitonic absorption [38]. This absorption edge is significantly minimized in $\mathrm{ZnS} / \mathrm{CdS}$ and $\mathrm{CdS} / \mathrm{ZnS}$ heterojunction thin films, and the smoothness of the absorption edge improved. This signifies the use of $\mathrm{CdS}$ as a substrate for $\mathrm{ZnS}$ deposition minimizes defect states leading to minimized visible light absorption, which is important for materials used as window layers of solar cells [39].

The optical absorption coefficient, $\alpha$, of the thin films was calculated using Lambert's equation:

$$
\alpha=2.303 \frac{A}{d}
$$

where $A$ is the optical absorbance, and $d$ is the film thickness.

The optical band gaps of the single and multilayer thin films were obtained using Tauc's relation using the obtained absorption coefficient [40]:

$$
(\alpha h v)^{n}=B\left(h v-E_{g}\right)
$$

where $B$ is the optical transition dependent constant, $h$ is Planck's constant, $v$ is the frequency of the radiation, $E_{g}$ is the band gap energy, and $n$ characterizes the transition type. The value of $n$ is 2 and $2 / 3$ for direct allowed and forbidden transitions, respectively, whereas the value of $n$ is $1 / 2$ and $1 / 3$ for indirect allowed and forbidden transitions, respectively. The analysis of Tauc's relation with the obtained absorption 
data of the single and heterojunction thin films revealed a straight line for $n=2$ immediately after the fundamental absorption edge, confirming that the samples possess direct optical bandgaps. The band gaps were obtained by extrapolating the linear portion of $(\alpha h v)^{2}$ vs. $(h v)$ curves towards the photon energy $(h v)$ axis. These plots for the single and heterojunction thin films are shown in Figure 2.

The bandgaps of CdS/glass, CdS/ZnS, ZnS/glass, and ZnS/ CdS thin films are equal to $2.45,2.25,2.55$, and $2.75 \mathrm{eV}$, respectively. The obtained bandgaps for all samples with the $\mathrm{ZnS}$ layer are smaller than that of the bulk $\mathrm{ZnS}$. This could be due to defect states and indirect transition which leads to the tailing in absorption [41]. A slight increase in the band gap and decrease in the absorbance of the $\mathrm{ZnS} / \mathrm{CdS}$ heterojunction compared to the $\mathrm{ZnS} /$ glass single layer indicates the decrease in the defect states in replacing the glass substrate by the CdS layer. The better crystallinity of the $\mathrm{ZnS} / \mathrm{CdS}$ heterojunction than the $\mathrm{ZnS} /$ glass single layer supports this anticipation. The decrease in the bandgap of the CdS/ZnS heterostructure thin film compared to the CdS/glass single layer thin film may be resulted from the increase in the grains size as discussed in Section 3.3. The interface between $\mathrm{ZnS}$ and CdS layers is so homogenized that a single bandgap is observed for both $\mathrm{ZnS} / \mathrm{CdS}$ and $\mathrm{CdS} / \mathrm{ZnS}$ heterojunction thin films. The broader transition edge for CdS/ZnS heterojunction than the CdS/glass single layer infers the nonuniform distribution of grains size and presence of defects in it $[42,43]$.

3.2.2. Optical Constants and Solid State Properties. The optical constants and solid state properties of CdS/glass, $\mathrm{CdS} / \mathrm{ZnS}, \mathrm{ZnS} /$ glass, and $\mathrm{ZnS} / \mathrm{CdS}$ thin films were studied employing the optical absorption theory [44]. The energy conservation law leads to the relation between reflectance $(R)$, transmittance $(T)$, and absorbance $(A)$ as [45]

$$
R+T+A=1,
$$

where transmittance is related to the measured absorbance by $T=10^{-A}$. When light passes through a lossy medium, it can experience loss in its energy due to phenomena such as scattering, free carrier absorption, generation of phonons, and photogeneration. This loss is taken in to account in the complex refractive index, $n^{*}$, as [46]

$$
n^{*}=n+i k,
$$

where the real part $n$ is the refractive index and indicates the phase velocity, while the imaginary part $k$ is called the extinction coefficient and indicates the amount of attenuation when the electromagnetic wave propagates through the material [47]. The refractive index $(n)$ and the extinction coefficient $(k)$ were obtained from the relations as follows [48]:

$$
\begin{aligned}
& n=\frac{1+R^{(1 / 2)}}{1-R^{(1 / 2)},} \\
& k=\frac{\alpha \lambda}{4 \pi},
\end{aligned}
$$

where $\lambda$ is the incident light wavelength.

Figure 3 shows the plots of refractive index and the extinction coefficient of single and heterojunction thin films of $\mathrm{CdS}$ and $\mathrm{ZnS}$ against the incident photon energy. The refractive index of the CdS/glass single layer thin film increases from 1.6 to 2.5 almost linearly with photon energy before and after the band gap energy; however, around the band gap edge, the refractive index increases abruptly. For the $\mathrm{CdS} / \mathrm{ZnS}$ heterojunction thin film, the refractive index decreases from 2.65 to 2.1 with photon energy. The refractive index of the $\mathrm{ZnS} /$ glass single layer thin film is nearly constant about 2.65 irrespective of the photon energy. For $\mathrm{ZnS} /$ CdS heterojunction thin film, the refractive index increases linearly with photon energy from 2.1 to 2.7. The extinction coefficient of the CdS/glass thin film decreases up to the band gap energy and then increases forming a valley; next to the band gap energy, its extinction coefficient increases linearly. The extinction coefficients of CdS/ZnS heterojunction and $\mathrm{ZnS} /$ glass single layer thin films increase in similar manner; they initially increase and then decrease forming a smooth curve with photon energy. The extinction coefficient of the $\mathrm{ZnS} / \mathrm{CdS}$ heterojunction thin film decreases linearly. Except the refractive index of the single layer $\mathrm{ZnS} /$ glass thin film, both the refractive index and extinction coefficients of the single and heterojunctions thin films are obviously influenced by photon energy.

Fundamental electronic transition in the semiconductor thin film is intimately related to the frequency dependent complex dielectric constant and expressed as [46, 49]

$$
\varepsilon^{*}=\varepsilon_{r}+i \varepsilon_{i}=\left(n^{2}-k^{2}\right)+i 2 n k
$$

The frequency-dependent dielectric parameters are the basic electrical properties of materials that reveal the electrical processes taking place in materials [50]. Figure 4 shows the plots of the real $\left(\varepsilon_{r}\right)$ and imaginary $\left(\varepsilon_{i}\right)$ dielectric constants of CdS/glass, CdS/ZnS, ZnS/glass, and ZnS/CdS single and heterojunction thin films against the incident photon energy. It can be observed that the imaginary parts of the dielectric constants of the $\mathrm{CdS} /$ glass and $\mathrm{CdS} / \mathrm{ZnS}$ thin films are larger than the real part. To the contrary, the real part of the dielectric constant of the ZnS/glass thin film is larger than that of the imaginary part. In the case of $\mathrm{ZnS} /$ CdS, the imaginary part is larger than the real part for incident photon energy less than $2.5 \mathrm{eV}$, and the reverse is true for photon energy larger than $2.5 \mathrm{eV}$. The imaginary dielectric constants of both CdS/ZnS and $\mathrm{ZnS} / \mathrm{CdS}$ heterojunction thin films show decreasing nature with increasing incident photon energy and that of $\mathrm{ZnS} /$ glass thin film is independent of the incident photon energy. However, the imaginary dielectric constant of the CdS/glass thin film increases with incident photon energy. The $\mathrm{ZnS} /$ glass single layer thin film has the highest real dielectric constant and the least imaginary dielectric constant among all the samples. The highest dielectric constant of the $\mathrm{ZnS} /$ glass single layer thin film confirms that it has more dipole nature under electric fields than other films [51]. The increase in the dielectric constant of this film with the photon energy reveals 

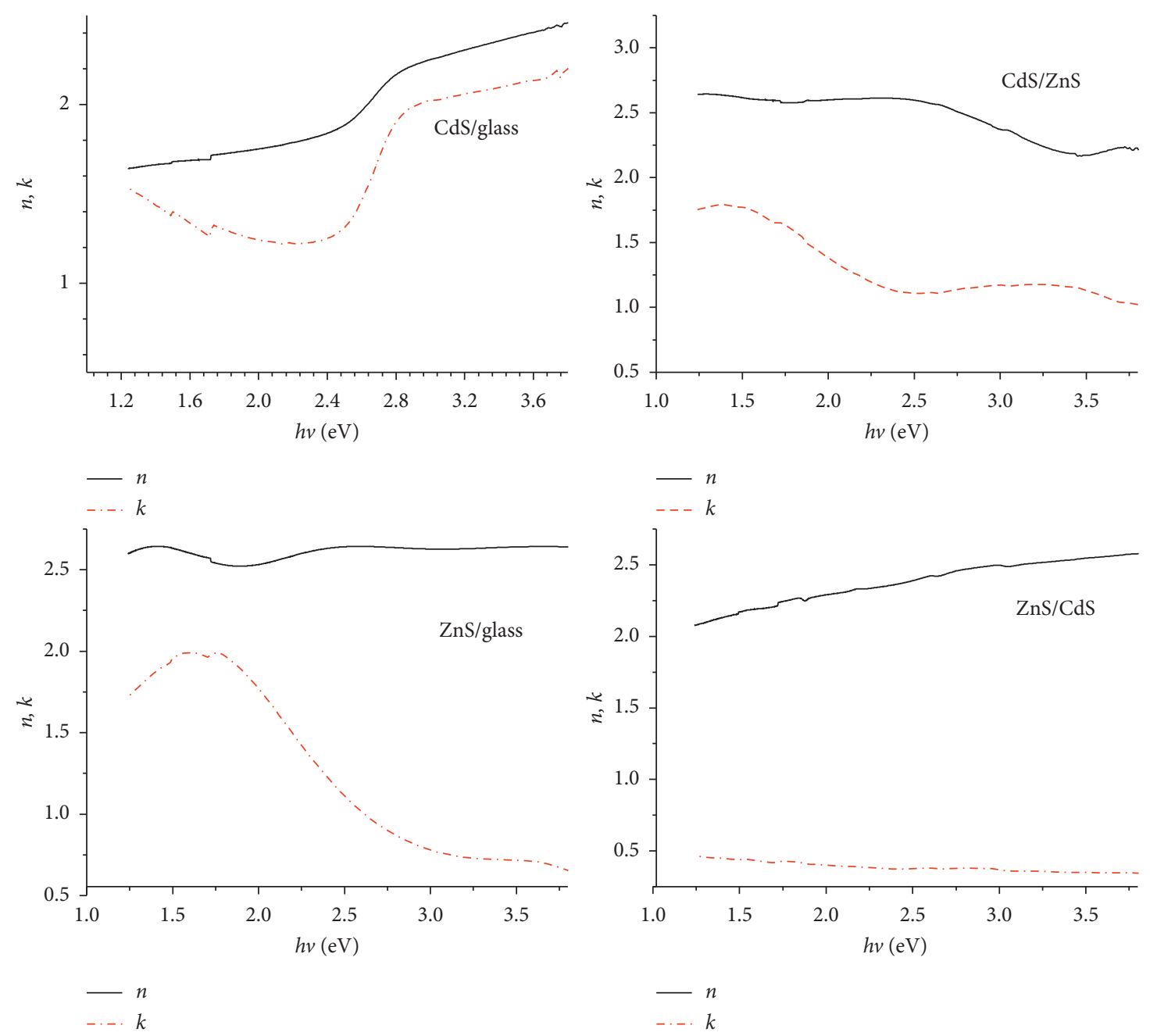

FIgURe 3: Refractive index $n$ and extinction coefficient $k$ of CdS/glass, CdS/ZnS, ZnS/glass, and ZnS/CdS thin films.

the accumulation of surface charges at the grain boundary with increasing photon energy $[52,53]$.

The optical conductivity $(\sigma)$ which refers the electrical conductivity in the presence of an alternating electric field is calculated from the following relation:

$$
\sigma=\frac{\alpha n c}{4 \pi}
$$

where $c$ is the speed of light in vacuum. Figure 5 shows the optical conductivity of CdS/glass, CdS/ZnS, ZnS/glass, and $\mathrm{ZnS} / \mathrm{CdS}$ single and heterojunction thin films. The $\mathrm{ZnS} / \mathrm{CdS}$ heterojunction thin film has the least optical conductivity among the samples for all range of incident photon energy. The ZnS/glass single layer thin film has the highest optical conductivity for photon energy less than $2.52 \mathrm{eV}$, and the $\mathrm{CdS} /$ glass single layer has the highest optical conductivity for photon energy greater than $2.57 \mathrm{eV}$. According to Jonscher, the origin of the frequency dependence of conductivity lies in the relaxation phenomena arising due to mobile charge carriers. From the figure, it can be seen that the optical conductivity increases with increasing photon energy, which could be attributed to the presence of space charges and increase in the extinction coefficient. Molecules having a permanent electric dipole moment, that can change its orientation when an electric field is applied, create space charge polarization $[52,54]$.

3.3. Surface Morphology and Composition Analysis. The SEM micrographs of CdS/glass, CdS/ZnS, ZnS/glass, and $\mathrm{ZnS} /$ $\mathrm{CdS}$ thin films are shown in Figure 6. The SEM micrograph of CdS/glass thin film shows spherical grains covering the substrate without cracks, pinholes, and voids. The surface morphology consists of compacted inner grains of average size $150 \mathrm{~nm}$ and few larger grains of size as large as $820 \mathrm{~nm}$ dispersed over the compacted inner grains. The grain size variation for inner grains is very small and that of outer grains is very large. These grain size distributions indicate that the inner layer of the film is formed by the ion-by-ion film deposition mechanism, and the outer larger grains could be resulted from clustering and coalescence of grains. The smooth optical absorption curve of the CdS/glass thin film also implies the uniform grain size distribution [55]. The surface morphology of the $\mathrm{ZnS} /$ glass thin film has very similar nature to that of the CdS/glass thin film. However, the average sizes for the inner compacted and the outer 

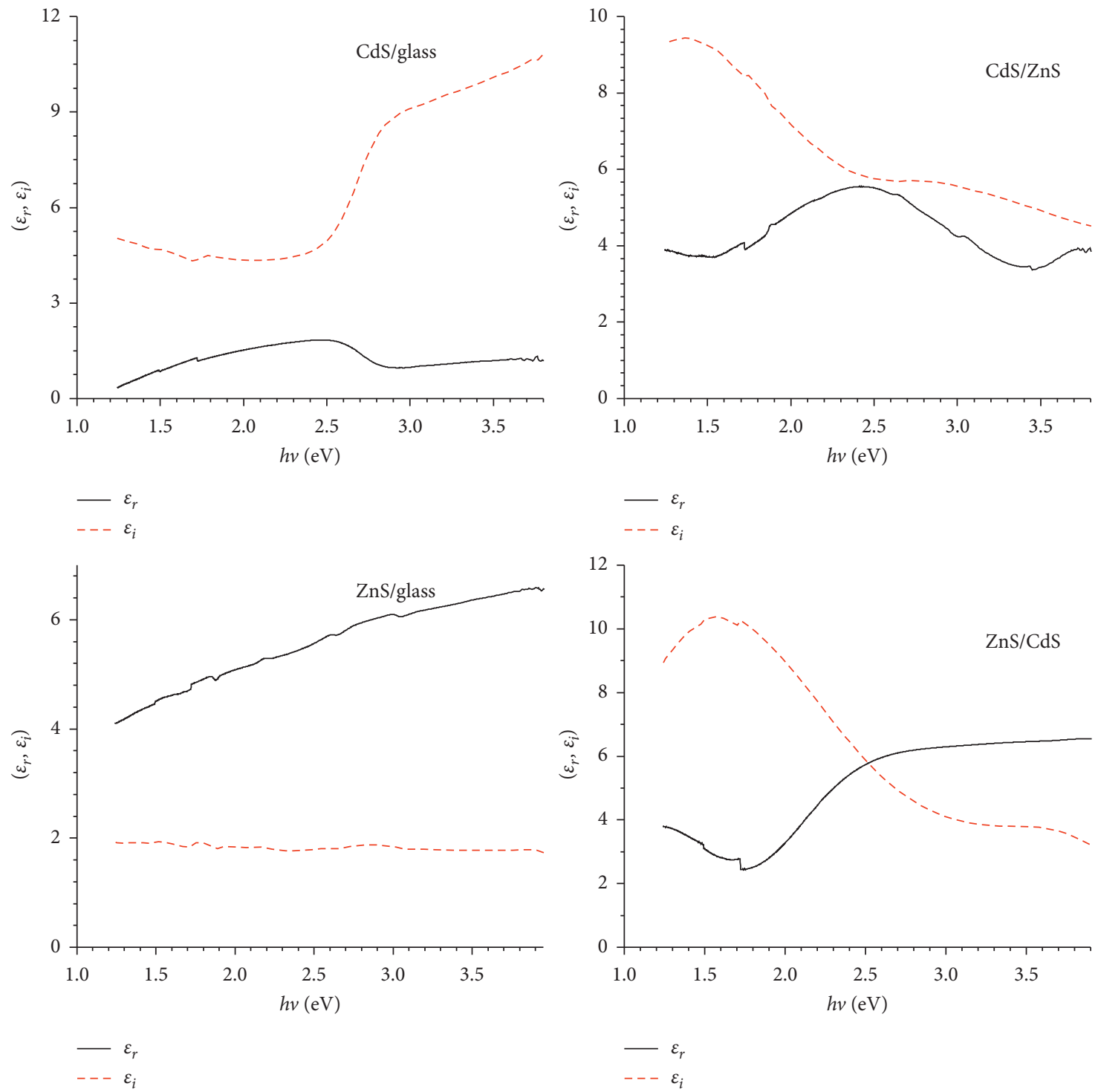

Figure 4: Plots of real $\left(\varepsilon_{r}\right)$ and imaginary $\left(\varepsilon_{i}\right)$ part of the dielectric constant $(\varepsilon)$ versus $h v$ for CdS/glass, CdS/ZnS, ZnS/glass, and ZnS/CdS thin films.

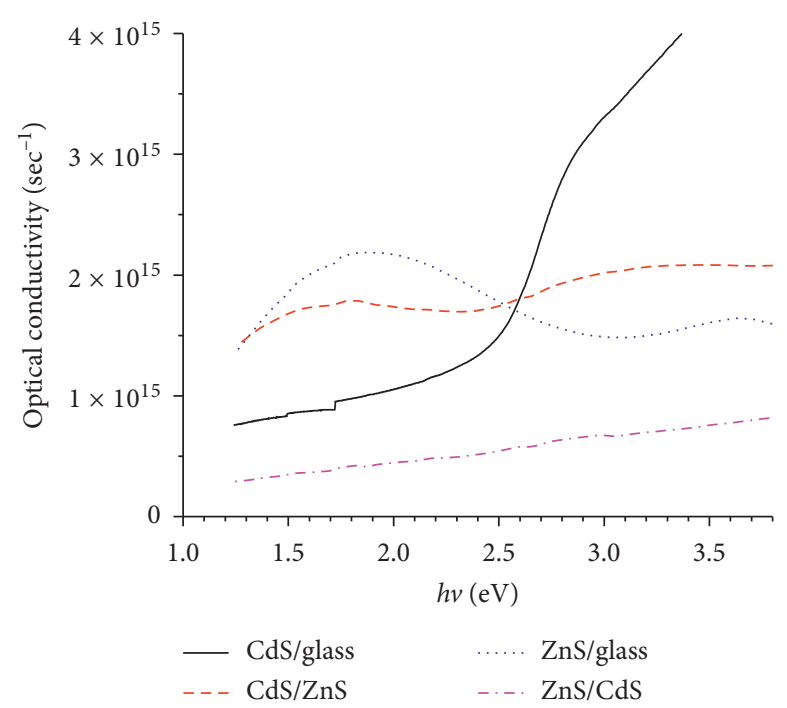

FIgURE 5: Plots of optical conductivity $(\sigma)$ versus photon energy $(h v)$ for CdS/glass, CdS/ZnS, ZnS/glass, and ZnS/CdS thin films. 

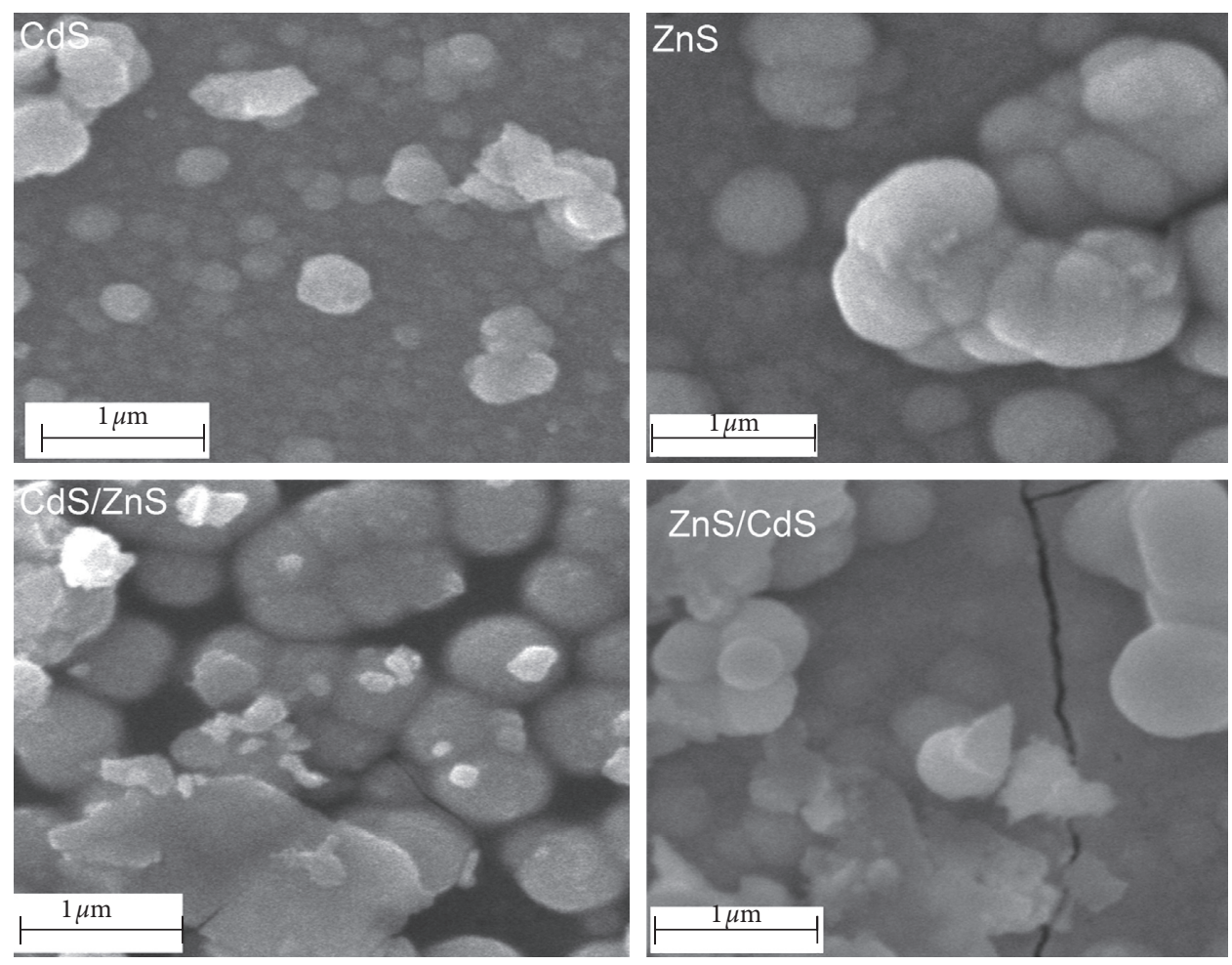

FIGURE 6: Surface morphology of single and multilayers of CdS and ZnS thin films.

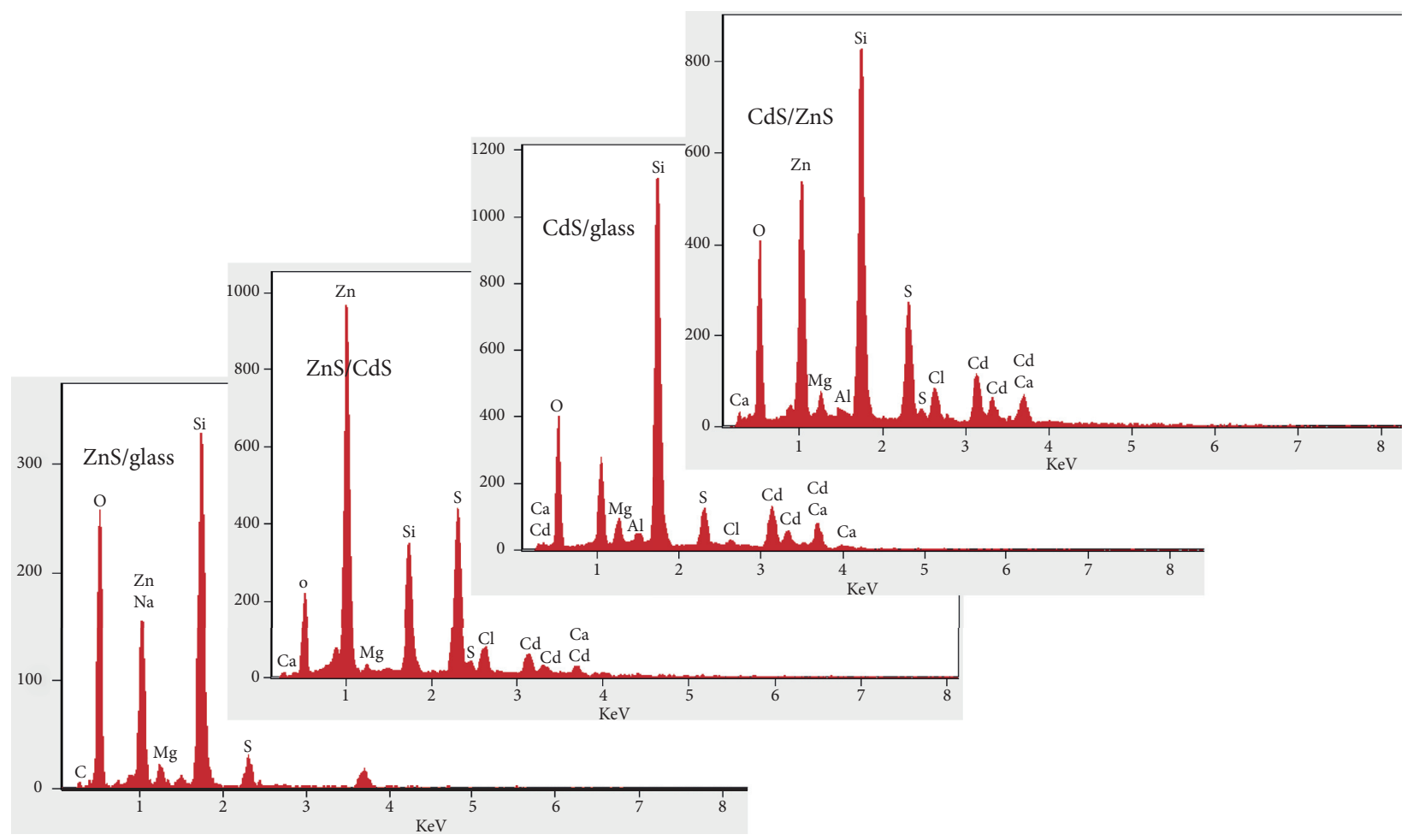

Figure 7: EDAX spectrum of the ZnS/glass, ZnS/CdS, CdS/glass, and CdS/ZnS.

dispersed grains are significantly larger than that of the corresponding $\mathrm{CdS} /$ glass thin film with the average grain sizes $445 \mathrm{~nm}$ and $1.55 \mu \mathrm{m}$, respectively. The SEM micrograph of CdS/ZnS heterojunction thin film is dominated by spherical grains of average size $700 \mathrm{~nm}$ with very narrow grain size variations and several voids. Few irregular 
shaped grains of size as large as $2.5 \mu \mathrm{m}$ are also observed. The absence of CdS peaks in the XRD pattern, the increased in the grain sizes, the presence of voids, and the absence of double band gaps in the $\mathrm{CdS} / \mathrm{ZnS}$ heterostructure thin film signify that the $\mathrm{Cd}$ and $\mathrm{S}$ ions were adsorbed on the existing $\mathrm{ZnS}$ surface grains rather than forming the $\mathrm{CdS}$ phase. The surface morphology of the $\mathrm{ZnS} / \mathrm{CdS}$ heterojunction thin film consists compacted background spherical grains without distinct boundary accompanied by few cracks. Few clusters of spherical grains are observed over the compact background. The SEM micrographs of the present work show the dependent of surface morphology on the type of substrate. Such substrate dependent morphology was reported by other researchers [56].

The elemental coposition of CdS/glass, CdS/ZnS, ZnS/ glass, and $\mathrm{ZnS} / \mathrm{CdS}$ thin films are qualitatively represented by the EDAX spectra in Figure 7. All the spectra confirmed the presence of the expected elements, i.e., $\mathrm{Cd}, \mathrm{Zn}$, and S. Other elements, such as $\mathrm{Ca}, \mathrm{O}, \mathrm{Al}, \mathrm{Na}, \mathrm{Mg}, \mathrm{Si}$, and $\mathrm{Cl}$, are resulted from the soda lime glass substrate which decreased in the heterojunction thin films particularly for $\mathrm{ZnS} / \mathrm{CdS}$. The atomic percentage ratio of $\mathrm{Cd}: \mathrm{S}$ is $48.7: 51.28$ in the $\mathrm{CdS} /$ glass thin film, and in the $\mathrm{ZnS} /$ glass thin films, the $\mathrm{Zn}: \mathrm{S}$ atomic percentage ratio is $49.86: 50.14$. The anion to cation ratios in the single-layered thin films are very close to $1: 1$ indicating that the thin films have a stoichiometric ratio. The elemental compositions of the $\mathrm{ZnS} / \mathrm{CdS}$ heterojunction thin film are $\mathrm{Cd}=6.65 \%, \mathrm{Zn}=35.37 \%$, and $\mathrm{S}=57.46 \%$, whereas the elemental compositions of the CdS/ZnS heterojunction thin film are $\mathrm{Cd}=19.47 \%, \mathrm{Zn}=25.99 \%$, and $\mathrm{S}=54.54 \%$. The percentage ratio of $\mathrm{Zn}$ is greater than that of $\mathrm{Cd}$ in both $\mathrm{ZnS}$ / $\mathrm{CdS}$ and $\mathrm{CdS} / \mathrm{ZnS}$ heterojunction thin films.

\section{Conclusion}

$\mathrm{ZnS} /$ glass, CdS/glass, $\mathrm{ZnS} / \mathrm{CdS}$, and $\mathrm{CdS} / \mathrm{ZnS}$ single layer and heterojunction thin films were synthesized at a $\mathrm{pH}$ of 2.5 and temperature $80^{\circ} \mathrm{C}$. Structural analysis confirmed the cubic structure with single peak along the (111) plane for $\mathrm{CdS} /$ glass and hexagonal structure for $\mathrm{ZnS} /$ glass single layer thin films. The XRD patterns of both $\mathrm{ZnS} / \mathrm{CdS}$ and $\mathrm{CdS} / \mathrm{ZnS}$ heterojunction thin films show only the hexagonal $\mathrm{ZnS}$ structure confirming the growth of inadequate CdS layer on the $\mathrm{ZnS}$ structure to diffract the X-ray. However, the $\mathrm{ZnS}$ layer grown on the CdS structure overshadows the X-ray diffraction from the inner $\mathrm{CdS}$ layer. The optical absorption curves for CdS/glass, ZnS/CdS, and CdS/ZnS thin films show smooth fundamental transition curves implying uniform distribution of grains sizes, minimum defect states, and homogenized interface between $\mathrm{ZnS}$ and $\mathrm{CdS}$. The optical conductivity and the components of complex refractive index and dielectric constant of the single layer and heterojunction thin films are incident photon energy dependent. The surface morphologies of all the films are formed from spherical grains. The SEM micrographs of CdS/glass, $\mathrm{ZnS} /$ glass, and $\mathrm{ZnS} / \mathrm{CdS}$ showed small and compacted spherical background grains followed by dispersed larger grains on the surface. The single-layered CdS/glass and ZnS/ glass thin films were free from cracks and voids; however, couples of voids and very few cracks were observed for CdS/ $\mathrm{ZnS}$ and $\mathrm{ZnS} / \mathrm{CdS}$ heterojunction thin films, respectively. The elemental composition of the single-layered films has nearly $1: 1$ ratio between metallic and nonmetallic ions. In the case of heterojunction thin films, the sulfur ion has a slight dominance over the metallic ions. The elemental analysis of $\mathrm{ZnS} / \mathrm{CdS}$ and $\mathrm{CdS} / \mathrm{ZnS}$ heterojunctions has shown the dominance of $\mathrm{Zn}$ ion over $\mathrm{Cd}$ ion.

\section{Data Availability}

The XRD and UV-VIS data used to support the findings of this study are available from the corresponding author upon request.

\section{Conflicts of Interest}

The authors declare that they have no conflicts of interest.

\section{Acknowledgments}

The authors acknowledge Hawassa University for funding this research work.

\section{References}

[1] T. Abza, F. K. Ampong, F. G. Hone, I. Nkrumah, R. K. Nkum, and F. Boakye, "A new route for the synthesis of CdS thin films from acidic chemical baths," International Journal of Thin Films Science and Technology, vol. 6, no. 2, pp. 67-71, 2017.

[2] T. Abza, F. K. Ampong, F. G. Hone, R. K. Nkum, and F. Boakye, "Preparation of cadmium zinc sulfide (Cd1-xZnxS) thin films from acidic chemical baths," Thin Solid Films, vol. 666, pp. 28-33, 2018.

[3] F. T. Munna, P. Chelvanathan, K. Sobayel et al., "Effect of zinc doping on the optoelectronic properties of cadmium sulphide (CdS) thin films deposited by chemical bath deposition by utilising an alternative sulphur precursor," Optik, vol. 218, Article ID 165197, 2020.

[4] J. Kim, C. R. Lee, V. K. Arepalli, S.-J. Kim, W.-J. Lee, and Y.-D. Chung, "Role of hydrazine in the enhanced growth of zinc sulfide thin films using chemical bath deposition for $\mathrm{Cu}(\mathrm{In}, \mathrm{Ga}) \mathrm{Se} 2$ solar cell application," Materials Science in Semiconductor Processing, vol. 105, Article ID 104729, 2020.

[5] S. Yılmaz et al., "Surface modification of CBD-grown CdS thin films for hybrid solar cell applications," Optik, vol. 185, pp. 256-263, 2019.

[6] M. I. M. Palma et al., "Effect of wavelengths on the structure, morphology and optoelectronic properties of cadmium sulfide thin films by laser assisted chemical bath deposition," Materials Today: Proceedings, vol. 33, pp. 1434-1443, 2020.

[7] A. M. Ali, Y. Yusoff, L. M. Ali et al., "Synthesis of sphere-likecrystal CdS powder and thin films using chemical residue in chemical bath deposition (CBD) for thin film solar cell application," Solar Energy, vol. 173, pp. 120-125, 2018.

[8] A. I. Trejo-Ramos, I. J. González-Chan, and A. I. Oliva, "Physical properties of chemically deposited $\mathrm{ZnS}$ thin films: role of the solubility curves and species distribution diagrams," Materials Science in Semiconductor Processing, vol. 118, Article ID 105207, 2020.

[9] A. M. Al-Diabat, N. M. Ahmed, M. R. Hashim, and M. A. Almessiere, "Growth of $\mathrm{ZnS}$ thin films using chemical 
spray pyrolysis technique," Materials Today: Proceedings, vol. 17, pp. 912-920, 2019.

[10] M. Hajimazdarani et al., "Enhanced optical properties and photodetection behavior of $\mathrm{ZnS}$ thin film deposited by electron beam evaporation upon doping with europium oxide," Ceramics International, vol. 46, no. 16, pp. 28382-28389, 2020.

[11] A. Kumar, M. Khan, J. He, and I. M. C. Lo, "Recent developments and challenges in practical application of visible-light-driven $\mathrm{TiO}_{2}$-based heterojunctions for PPCP degradation: a critical review," Water Research, vol. 170, Article ID 115356, 2020.

[12] O. A. Arotiba, B. O. Orimolade, and B. A. Koiki, "Visible light driven photoelectrocatalytic semiconductor heterojunction anodes for water treatment applications," Current Opinion in Electrochemistry, vol. 22, 2020.

[13] J. S. Jang, H. G. Kim, and J. S. Lee, "Heterojunction semiconductors: a strategy to develop efficient photocatalytic materials for visible light water splitting," Catalysis Today, vol. 185 , no. 1, pp. 270-277, 2012.

[14] V. Pačebutas et al., "Band-offsets of GaInAsBi-InP heterojunctions," Infrared Physics \& Technology, vol. 109, Article ID 103400, 2020.

[15] S. Zhu, Y. Zhang, X. Qian, X. Wang, and W. Su, "Zn defectmediated Z-scheme electron-hole separation in AgIn5S8/ZnS heterojunction for enhanced visible-light photocatalytic hydrogen evolution," Applied Surface Science, vol. 504, Article ID 144396, 2020.

[16] H. Fang, C. Battaglia, C. Carraro et al., "Strong interlayer coupling in van der Waals heterostructures built from singlelayer chalcogenides," Proceedings of the National Academy of Sciences, vol. 111, no. 17, pp. 6198-6202, 2014.

[17] J. Kundu, B. K. Satpathy, and D. Pradhan, "Compositioncontrolled CdS/ZnS heterostructure nanocomposites for efficient visible light photocatalytic hydrogen generation," Industrial \& Engineering Chemistry Research, vol. 58, no. 51, pp. 22709-22717, 2019.

[18] A. García-Barrientos, H. Gomez-Pozos, E. Villicaña-Ortiz, and L. Cruz-Netro, "Comparative study of CdS and CdS/ZnS thin films deposited by CBD as a buffer layer solar cell," Microscopy and Microanalysis, vol. 24, no. S1, pp. 1548-1549, 2018.

[19] O. Echendu and I. Dharmadasa, "Graded-bandgap solar cells using all-electrodeposited ZnS, CdS and CdTe thin-films," Energies, vol. 8, no. 5, pp. 4416-4435, 2015.

[20] H. Kumar, A. Kumari, and R. R. Singh, "Tunable narrow emission in $\mathrm{ZnS} / \mathrm{CdS} / \mathrm{ZnS}$ quantum well structures prepared by aqueous route," Optical Materials, vol. 69, pp. 23-29, 2017.

[21] K. Hasanirokh and A. Asgari, "Modeling and studying of white light emitting diodes based on CdS/ZnS spherical quantum dots," Optical Materials, vol. 81, pp. 129-133, 2018.

[22] I. O. Oladeji and L. Chow, "Synthesis and processing of CdS/ ZnS multilayer films for solar cell application," Thin Solid Films, vol. 474, no. 1-2, pp. 77-83, 2005.

[23] X. Wang and W. Zhang, "Chemical depositing of CdS/ZnS composition nanostructure modified $\mathrm{TiO} 2$ thin film," Chalcogenide Letters, vol. 11, no. 8, pp. 389-395, 2014.

[24] N. Dahbi and D.-E. Arafah, "Thermoluminescence characteristics of $\mathrm{ZnS} \backslash \mathrm{CdS} \backslash \mathrm{ZnS}$ window multilayer thin film for solar cell applications," Energy Procedia, vol. 18, pp. 14461451, 2012.

[25] N. Dahbi and D.-E. Arafah, "Characterization and processing of CdS/ZnS thin layer films deposited onto quartz for solar cell applications," Energy Procedia, vol. 18, pp. 85-90, 2012.
[26] E. Okechukwu and D. Okoli, "Optical and structural properties of electrodeposited CdS/ZnS compound thin films and their possible applications," Journal of Materials Sciences and Applications, vol. 1, no. 6, pp. 282-291, 2015.

[27] M. Rincon, M. Martınez, and M. Miranda-Hernández, "Nanostructured vs. polycrystalline CdS/ZnS thin films for photocatalytic applications," Thin Solid Films, vol. 425, no. 12, pp. 127-134, 2003.

[28] R. H. Castillo et al., "Study of ZnS/CdS structures for solar cells applications,” Optik, vol. 148, pp. 95-100, 2017.

[29] X. Zeng, W. Zhang, J. Cui, M. Zhou, and H. Chen, "Charge transfer and optical properties of wurtzite-type $\mathrm{ZnS} /(\mathrm{CdS} /$ $\mathrm{ZnS}) \mathrm{n}(n=2,4,8)$ superlattices," Materials Research Bulletin, vol. 50, pp. 359-364, 2014.

[30] M. A. Barote, A. A. Yadav, and E. U. Masumdar, "Synthesis, characterization and photoelectrochemical properties of n-CdS thin films," Physica B: Condensed Matter, vol. 406, no. 10, pp. 1865-1871, 2011.

[31] G. Hodes, Chemical Solution Deposition of Semiconductor Films, CRC Press, Boco Raton, FL, USA, 2002.

[32] M. Ouafi, B. Jaber, L. Atourki et al., "In situ low-temperature chemical bath deposition of CdS thin films without thickness limitation: structural and optical properties," International Journal of Photoenergy, vol. 2018, Article ID 4549154, 2018.

[33] A. Kariper, E. Güneri, F. Göde, C. Gümüş, and T. Özpozan, "The structural, electrical and optical properties of CdS thin films as a function of $\mathrm{pH}$, " Materials Chemistry and Physics, vol. 129, no. 1-2, pp. 183-188, 2011.

[34] P. Roy, J. R. Ota, and S. K. Srivastava, "Crystalline ZnS thin films by chemical bath deposition method and its characterization," Thin Solid Films, vol. 515, no. 4, pp. 1912-1917, 2006.

[35] J. Liu, A. Wei, and Y. Zhao, "Effect of different complexing agents on the properties of chemical-bath-deposited $\mathrm{ZnS}$ thin films," Journal of Alloys and Compounds, vol. 588, pp. 228234, 2014.

[36] Y. Waseda, E. Matsubara, and K. Shinoda, X-ray Diffraction Crystallography: Introduction, Examples and Solved Problems, Springer Science \& Business Media, Berlin, Germany, 2011.

[37] M. Cao, L. Li, B. L. Zhang et al., "Influence of substrates on the structural and optical properties of ammonia-free chemically deposited CdS films," Journal of Alloys and Compounds, vol. 530, pp. 81-84, 2012.

[38] J. Singh, "Optical properties of condensed matter and applications,” vol. 6, John Wiley \& Sons, Singapore, 2006.

[39] M. K. S. B. Rafiq et al., "WS 2: a new window layer material for solar cell application," Scientific Reports, vol. 10, no. 1, pp. 1-11, 2020.

[40] A. J. Khimani, S. H. Chaki, T. J. Malek, J. P. Tailor, S. M. Chauhan, and M. P. Deshpande, "Cadmium sulphide (CdS) thin films deposited by chemical bath deposition (CBD) and dip coating techniques-a comparative study," Materials Research Express, vol. 5, no. 3, p. 036406, Article ID 036406, 2018.

[41] S. P. Patel, J. C. Pivin, R. Chandra, D. Kanjilal, and L. Kumar, "Intrinsic defects and structural phase of $\mathrm{ZnS}$ nanocrystalline thin films: effects of substrate temperature," Journal of $M a$ terials Science: Materials in Electronics, vol. 27, no. 6, pp. 5640-5645, 2016.

[42] N. S. Das, P. K. Ghosh, M. K. Mitra, and K. K. Chattopadhyay, "Effect of film thickness on the energy band gap of nanocrystalline CdS thin films analyzed by spectroscopic ellipsometry," Physica E: Low-Dimensional Systems and Nanostructures, vol. 42, no. 8, pp. 2097-2102, 2010. 
[43] Z. Makhdoumi-Kakhaki, A. Youzbashi, P. Sangpour, N. Naderi, and A. Kazemzadeh, "Effects of film thickness and stoichiometric on the electrical, optical and photodetector properties of CdS quantum dots thin films deposited by chemically bath deposition method at different bath temperature," Journal of Materials Science: Materials in Electronics, vol. 27, no. 12, pp. 12931-12939, 2016.

[44] J. I. Pankove, Optical Processes in Semiconductors, Courier Corporation, Chelmsford, MA, USA, 1975.

[45] S. M. Chauhan, S. H. Chaki, M. P. Deshpande, J. P. Tailor, and A. J. Khimani, "Characterization of CBD deposited CuInSe 2 thin film," Materials Science in Semiconductor Processing, vol. 74, pp. 329-335, 2018.

[46] D. Tiwari, T. K. Chaudhuri, T. Shripathi, U. Deshpande, and V. G. Sathe, "Structural and optical properties of layer-bylayer solution deposited Cu2SnS3 films," Journal of Materials Science: Materials in Electronics, vol. 25, no. 9, pp. 3687-3694, 2014.

[47] E. Hecht, Optics-Addison, Wesley, Boston, MA, USA, 2002.

[48] S. H. Chaki, M. P. Deshpande, and J. P. Tailor, "Characterization of $\mathrm{CuS}$ nanocrystalline thin films synthesized by chemical bath deposition and dip coating techniques," Thin Solid Films, vol. 550, pp. 291-297, 2014.

[49] T. Hurma, "Studies of structural, optical and electrical properties of nanostructured ZnS:F films," Optik, vol. 174, pp. 324-331, 2018.

[50] S. Suresh, "Synthesis, structural and dielectric properties of zinc sulfide nanoparticles," International Journal of Physical Sciences, vol. 8, no. 21, pp. 1121-1127, 2013.

[51] S. Thirumavalavan, K. Mani, and S. Sagadevan, "Studies on structural, surface morphology and optical properties of zinc sulphide $(\mathrm{ZnS})$ thin films prepared by chemical bath deposition," International Journal of Physical Sciences, vol. 10, no. 6, pp. 204-209, 2015.

[52] N. Panda, B. N. Parida, R. Padhee, and R. N. P. Choudhary, "Structural, dielectric and electrical properties of the $\mathrm{Ba}_{2} \mathrm{BiNbO}_{6}$ double perovskite," Journal of Materials Science: Materials in Electronics, vol. 26, no. 6, pp. 3797-3804, 2015.

[53] J. Koaib, N. Bouguila, H. Abassi et al., "Dielectric and electrical properties of annealed $\mathrm{ZnS}$ thin films. The appearance of the OLPT conduction mechanism in chalcogenides," RSC Advances, vol. 10, no. 16, pp. 9549-9562, 2020.

[54] N. A. Bakr, N. N. Jandow, and N. F. Habubi, "Optical and dispersion parameters of $\mathrm{ZnS}$ thin films prepared by flash evaporation method," International Letters of Chemistry, Physics and Astronomy, vol. 20, 2014.

[55] L. Wang, X.-T. Tao, J.-X. Yang, Y. Ren, Z. Liu, and M.-H. Jiang, "Preparation and characterization of the $\mathrm{ZnS}$ nanospheres with narrow size distribution," Optical Materials, vol. 28, no. 8-9, pp. 1080-1083, 2006.

[56] P. O'Brien et al., "Chemical bath deposition of cadmium sulphide on silicon nitride: influence of surface treatment on film growth," Materials Letters, vol. 61, no. 1, pp. 284-287, 2007. 